\title{
HIGH VOLUME CAMP SURGERIES - A CLINICAL STUDY
}

D. N. Prakash, K, Sathish, Sankalp Singh Sharma, Soujanya. K, Savitha Patil.
1. Assistant Professor. Department of Ophthalmology, MMC \& RI, Mysore,
2. Associate Professor. Department of Ophthalmology, MMC \& RI, Mysore,
3. PG Student. Department of Ophthalmology, MMC \& RI, Mysore,
4. PG Student. Department of Ophthalmology, MMC \& RI, Mysore,
5. PG Student. Department of Ophthalmology, MMC \& RI, Mysore,

\section{CORRESPONDING AUTHOR:}

Dr. D. N. Prakash,

"Bhuvi", No. 52,17th Main Road,

Kamakshi Hospital Road, Near Kuvempu School,

Saraswathipuram, Mysore- 570009.

E-mail: bhanup7@yahoo.com

\section{KEY WORDS: Cataract, eye camp surgeries}

INTRODUCTION: The number of blind persons in India in 2000 was estimated to be 18.7 million, of which 9.5 million were cataract -related. If there is no change in the current trend of blindness, the number of blind persons in India would increase to 31.6 million in 2020. If effective strategies are put in place to eliminate $95 \%$ of blindness due to cataract by 2020 , blindness in 15.6 million persons would be prevented who would otherwise be blind in 2020, and 82 million blind person-year would be prevented [1]. In 2000, 3.5 million cataract operations were performed but this remains insufficient to treat the backlog and the newly blind[2]. Productivity per individual surgeon/unit should be increased through a high volume, high quality cataract surgery approach to solve the problem of India's curable blind[3][4][5][6]. The World Health Organization global initiatives have called for a dramatic increase in surgical volumes worldwide ${ }^{[4]}$. However, it is becoming evident that outcomes of cataract surgeries are not always good and this aspect of surgical services must be further examined. Hence in this study an attempt has been made to analyze the results of 6000 surgeries performed by experienced surgeons utilizing the technique of manual small incision cataract surgery.

AIM: To study the outcome of high volume cataract surgeries in camps in terms of duration of surgery, visual acuity, complications and their management.

INCLUSION CRITERIA: Visually significant cataracts - Posterior subcapsular cataract, Nuclear sclerosis grade II-IV, Mature cataract, Hyper-mature cataract.

\section{EXCLUSION CRITERIA:}

1. Cataract with retinal pathology like macular lesions, Diabetic \& vascular retinopathy etc.

2. Cataract with Pseudo Exfoliation syndrome

3. Cataract with advanced Glaucomatous cupping

4. Complicated cataract

5. Subluxated cataract

6. Paediatric cataract

7. Traumatic cataract

8. Corneal opacity 


\section{Posterior polar cataract}

MATERIALS \& METHODS: A study was conducted at NGO Ophthalmology, Mysore between April 2009 and March 2011. A retrospective analysis of 6000 cases meeting the inclusion and exclusion criteria were selected for this study. Initial screening was done by optometrists and later examined by surgeons at the hospital on the same day. Detailed history, examinations and investigations were carried out by the resident doctors like slit lamp Biomicroscopy, Tonometry, Lacrimal sac syringing, Fundus examination, Keratometry and A-scan biometry.

Patients were posted for surgery on the next day and 2 experienced surgeons performed all the surgeries.

SURGICAL STEPS: After the Peribulbar anaesthesia, eye was painted with Povidone Iodine (Betadine) and draped. Septidine (5\%) eye drops were applied in conjunctival cul de sac. Superior rectus bridle suture was put. Fornix based conjunctival flap made. Site of incision was chosen according to preoperative keratometry reading. Size of incision ranged from 6 to $7 \mathrm{~mm}$ depending upon the hardness of cataract. Side port was made with lancetip. Capsular staining was done with $0.5 \%$ Trypan blue. Continuous curvilinear capsulorhexis / can opener capsulotomy was done. Anterior chamber was entered with $3.2 \mathrm{~mm}$ keratome. Hydrodissection was done and nucleus prolapsed into $\mathrm{AC}$ and delivered out by viscoexpression. Remaining cortical matter was removed using irrigation-aspiration canula. A $6.0 \mathrm{~mm}$ optic, $12.5 \mathrm{~mm}$ overall diameter PMMA IOL was placed in-th-bag/sulcus. AC was formed. Subconjunctival injection of Dexamethasone and Gentamycin was given.

Patients were examined on the first post operative day, 1 week and at the end of 6 week by the surgeons. Refraction and spectacle correction was given at the end of 6 weeks.

\section{RESULTS: 1.}

Age: ranged from 50 to 80 yrs.

\begin{tabular}{|l|l|l|}
\hline age & no. of patients & percentage \\
\hline $51-60$ yrs & 1200 & $20.00 \%$ \\
\hline $61-70$ & 2588 & $43.13 \%$ \\
\hline $71-80$ & 2212 & $36.81 \%$ \\
\hline Total & 6000 & \\
\hline Test statistics & \multicolumn{2}{|l|}{ Chi-square $=286.029$} \\
& DF $=2$, P-Value $=0.000$ \\
\hline
\end{tabular}

\section{Type of cataract:}

\begin{tabular}{|l|l|l|}
\hline type of cataract & no. of patients & percentage \\
\hline PSC & 2534 & $42.23 \%$ \\
\hline Nuclear Cataract(grade II - IV) & 1166 & $19.43 \%$ \\
\hline Mature cataract & 1524 & $25.41 \%$ \\
\hline Hypermature cataract & 776 & $12.93 \%$ \\
\hline Test statistics & $\begin{array}{l}\text { Chi-square }=537.376 \\
\text { DF }=3, \text { P-Value }=0.000\end{array}$ \\
\hline
\end{tabular}


3. Average duration of surgery: 4 min per case.

4. Intra operative complications: were graded according to OCTET grading (Oxford cataract treatment Evaluation Team)

Grade I : unlikely to need operation or unlikely to head to a drop in visual acuity(VA) by 2 lines of Snellen chart or more.

Grade II: May need treatment or may lead to some loss of vision (by 2 lines or more) but not suddenly.

Grade III: Needs further treatment or needs emergency action; or leads to loss of VA by 2 lines or more; or leads to loss of VA by 2 lines or more if no emergency action is taken.

\begin{tabular}{|l|l|l|l|l|}
\hline & $\begin{array}{l}\text { OCTET } \\
\text { Grading }\end{array}$ & $\begin{array}{l}\text { No. Of } \\
\text { patients }\end{array}$ & Percentage & \\
\hline $\begin{array}{l}\text { Tunnel-related } \\
\text { complication }\end{array}$ & I & 122 & $2.03 \%$ & \\
\hline DM detachment & I & 300 & $5 \%$ & \\
\hline $\begin{array}{l}\text { Posterior capsular rent } \\
\text { without vitreous loss }\end{array}$ & II & 124 & $2.06 \%$ & \\
\hline $\begin{array}{l}\text { Poaterior capsular rent } \\
\text { with vitreous loss }\end{array}$ & II & 30 & $0.5 \%$ & \\
\hline Iridodialysis & I & 6 & $0.1 \%$ & \\
\hline Test statistics & $\begin{array}{l}\text { Chi-square }=459.203 \\
\text { DF }=4, \text { P-Value }=0.000\end{array}$ \\
\hline
\end{tabular}

\section{Post operative complications:}

\begin{tabular}{|l|l|l|l|l|l|}
\hline & $\begin{array}{l}\text { octet } \\
\text { grading }\end{array}$ & $\begin{array}{l}\text { no. of } \\
\text { patients }\end{array}$ & $\begin{array}{l}\text { percentag } \\
\text { e }\end{array}$ & $\mathrm{x}^{2}$ & $\mathrm{p}$ \\
\hline Mild Iritis & I & 1860 & $31 \%$ & 449.42 & .000 \\
\hline Severe Iritis & II & 603 & $10.05 \%$ & 2278.92 & .000 \\
\hline Transient corneal oedema & I & 1860 & $31 \%$ & 449.424 & .000 \\
\hline Small hyphaema & I & 610 & $10.16 \%$ & 2263.12 & .000 \\
\hline Mild secondary glaucoma & I & 1200 & $20 \%$ & 1186.81 & .000 \\
\hline Residual cortex & II & 422 & $7.03 \%$ & 2716.95 & .000 \\
\hline Mild first day Hypopyon & I & 486 & $8.1 \%$ & 2555.35 & .000 \\
\hline Vitreous in AC & II & 10 & $0.16 \%$ & 3964.58 & .000 \\
\hline Cystoid Macular Oedema & II & 24 & $0.4 \%$ & 3915.46 & .000 \\
\hline Malosition of IOL & II & 720 & $12 \%$ & 2025.25 & .000 \\
\hline
\end{tabular}

Major complications like IOL drop, nucleus drop and post operativeendophthalmitis were not seen in the study.

Visual Acuity at the end of 6 weeks: 
a) UnCorrectedVisual Acuity:

\begin{tabular}{|c|c|c|}
\hline VA & NO. OF PATIENTS & PERCENTAGE \\
\hline $6 / 6-6 / 18$ & 4320 & $72 \%$ \\
\hline $6 / 24-6 / 60$ & 1078 & $17.19 \%$ \\
\hline$<6 / 60$ & 602 & $10.19 \%$ \\
\hline Test statistics & \multicolumn{2}{|c|}{$\begin{array}{c}\text { Chi-square }=1878.94 \\
\end{array}$} \\
& \multicolumn{2}{|c}{ DF P-Value $=0.000$} \\
\hline
\end{tabular}

b) Best Corrected Visual Acuity:

\begin{tabular}{|c|c|c|}
\hline VA & NO. OF PATIENTS & PERCENTAGE \\
\hline $6 / 6-6 / 18$ & 5405 & $90.05 \%$ \\
\hline $6 / 24-6 / 60$ & 475 & $7.92 \%$ \\
\hline$<6 / 60$ & 120 & $2 \%$ \\
\hline Test statistics & \multicolumn{2}{|c|}{$\begin{array}{c}\text { Chi-square }=4172.52 \\
\text { DF }=2, \text { P-Value }=0.000\end{array}$} \\
\hline
\end{tabular}

DISCUSSION: According to our study, average duration of surgery was 4 minutes per case, the similar study conducted by Venkatesh et al shown average duration of the surgery was 3.75 minutes. (6)

In our study intra operative complications were graded according to OCTET grading and was accounting for $8.56 \%$ which was less in comparison to study done by Venkatesh et al on Outcomes of high volume cataract surgeries in a developing country.(6)

Post-operative complications of our study was mild iritis $31 \%$, severe iritis $10.05 \%$, transient corneal oedema $31 \%$, hypheama $10.16 \%$, hypopyon $8,1 \%$, residual cortex $7.3 \%$ and malposition of IOL seen in $12 \%$. Post-operative complications were much higher in our study compared to the study done by Venkatesh et al on Outcomes of high volume cataract surgeries in a developing country.(6)

In this study the visual outcome following 6 weeks of surgery was found to be uncorrected visual acuity of $6 / 6$ to $6 / 18$ was achieved in $72 \%$ patients and the Best corrected visual acuity of $6 / 6$ to $6 / 18$ was achieved by $90.05 \%$ patients and visual acuity. The results were consistent with similar study done by conducted by Venkatesh et al.(6)

Conclusion - High volume camp surgeries using manual small incision cataract surgery can provide good visual outcome and increases the productivity per individual surgeon/unit. High volume camp surgeries reduce the burden of cataract blindness in community. Complications and poor visual outcome can be overcome by better pre-operative assessment.

\section{REFERENCES:}

1. Dandona L, Dandona R, John RK.Estimation of blindness in India from 2000 through 2020: implications for the blindness control policy. Natl Med J India. 2001 NovDec;14(6):327-34.

2. Natchiar G, Robin AL, Thulasiraj RD, KrishnaswamyS.Attacking the backlog of India's curable blind. The Aravind Eye Hospital model.Arch Ophthalmol. 1994 Jul;112(7):98793. 
3. Surka J, HussainS,Outcome of high volume cataract surgery at an academic hospital, S Afr Med J, 2001; 91:771-774.

4. R.D.Thulasiraj, R.Priya and S.Saravanan,High volume, high quality cataract surgery. Indian Journal of Community Health, 1997 Jul-Dec ;3(2)

5. Civerchia L, Ravindran RD, Apoorvananda SW, Ramakrishnan R, Balent A, Spencer $\mathrm{MH}$, Green D..High-volume intraocular lens surgery in a rural eye camp in India. Ophthalmic Surg Lasers. 1996 Mar;27(3):200-8

6. $\mathrm{R}$ Venkatesh $\mathrm{R}$ Muralikrishnan Linda Civerchia Balent, SKarthikPrakash,NVenkateshPrajna,Outcomes of high volume cataract surgeries in a developing country, Br J Ophthalmol 2005;89:1079-1083

7. Albert, Jakobiec. Principles and Practice of Ophthalmology. 2nd ed. Philadelphia:a.WB Saunders 2000;2:1540. 